\title{
The immunotherapeutic landscape in non-small cell lung cancer and its surgical horizons
}

\author{
Kristen E. Rhodin, MD, ${ }^{a}$ A. Justin Rucker, MD, MPH, ${ }^{a}$ Neal E. Ready, MD, PhD,,${ }^{\text {,c }}$ \\ Thomas A. D'Amico, MD, ${ }^{c, d}$ and Scott J. Antonia, MD, $\mathrm{PhD}^{\mathrm{b}, \mathrm{c}}$
}

\section{ABSTRACT}

Lung cancer continues to be a leading cause of cancer-related death worldwide. Despite tremendous advances in surgical technique, chemotherapy regimens, radiation, and targeted therapies, survival is $<50 \%$ at 5 years. Immunotherapy, specifically immune checkpoint inhibitors (ICIs), demonstrates promise as a solution to this clinical problem. Several agents have been Food and Drug Administration-approved for locally advanced and metastatic non-small cell lung cancer (NSCLC). Further studies are now exploring the use of these agents in the neoadjuvant and adjuvant settings. Although ICIs have demonstrated meaningful efficacy in NSCLC and other advanced malignancies, they are not without adverse toxicities. Furthermore, there are minimal data on their use in the perioperative period. Here we discuss the current domain of ICIs and their surgical implications in NSCLC. (J Thorac Cardiovasc Surg 2020;159:1616-23)

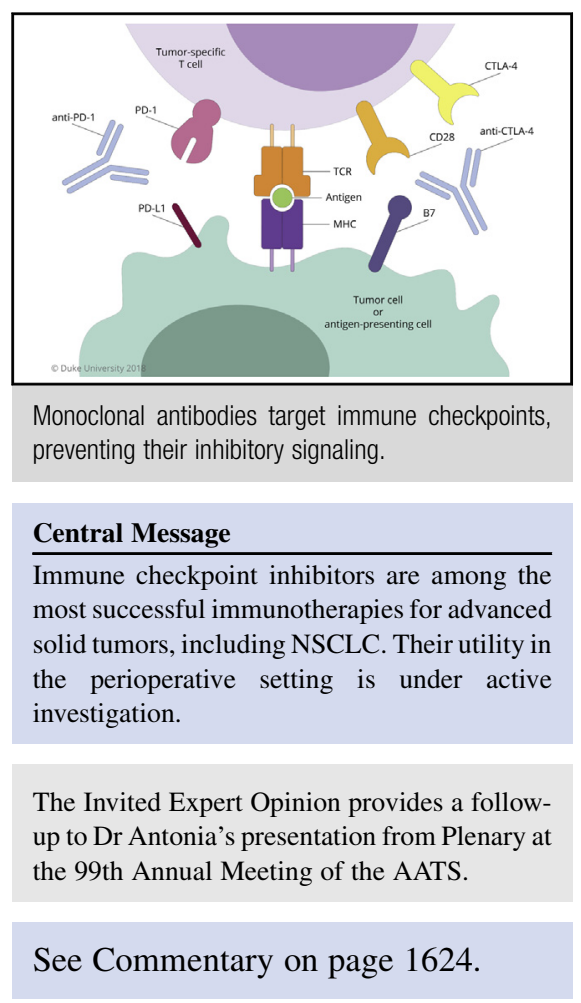

Feature Editor's Note-The content of thoracic surgery meetings and cardiothoracic surgery journals is rapidly being enriched for proceedings on immune checkpoint blockade. Randomized data have demonstrated improved oncologic and survival outcomes for patients with advanced and metastatic non-small cell lung cancer (NSCLC) treated with immunotherapy compared with the previous standard-of-care therapies that they replaced. A proliferation of neoadjuvant checkpoint

From the ${ }^{\mathrm{a}}$ Department of Surgery, ${ }^{\mathrm{b}}$ Division of Medical Oncology, Department of Medicine, and ${ }^{\mathrm{d}}$ Division of Cardiovascular and Thoracic Surgery, Department of Surgery, Duke University Medical Center, Durham, NC and ${ }^{\mathrm{c}}$ Duke Cancer Institute, Durham, NC.

Received for publication July 30, 2019; revisions received July 30, 2019; accepted for publication Aug 17, 2019; available ahead of print Dec 10, 2019.

Address for reprints: Kristen E. Rhodin, MD, Duke University Medical Center, 2301 Erwin Rd, Box 3443, Durham, NC, 27710 (E-mail: kristen.rhodin@ duke.edu). $0022-5223 / \$ 36.00$

Copyright (C) 2019 by The American Association for Thoracic Surgery

https://doi.org/10.1016/j.jtcvs.2019.08.138 inhibitor trials are enrolling patients with earlystage NSCLC, and thoracic surgeons are operating on patients treated with these drugs in the neoadjuvant and salvage setting. In the primer that follows, authorities in the field present arguably the most succinct and comprehensive crystallization of the state of the art in checkpoint inhibition for NSCLC. Thoracic surgeons of every professorial rank can expect to profit from the scholarly and practical insights provided in this feature article.

\section{-Bryan M. Burt, MD}

\section{INTRODUCTION TO IMMUNE CHECKPOINT BLOCKADE}

It has long been recognized that cancers arise due to a failure of normal immune surveillance mechanisms. ${ }^{1}$ Today, a tumor's ability to evade the immune system is recognized as a hallmark of cancer. ${ }^{1,2}$ Immunotherapy has subsequently emerged as a method to combat this feature 


\section{Abbreviations and Acronyms \\ FDA $=$ Food and Drug Administration \\ ICI = immune checkpoint inhibitor \\ NSCLC $=$ non-small cell lung cancer}

of malignancy by targeting the body's own immune system to enhance antitumor immunity. ${ }^{3}$ Among the available immunotherapeutic strategies, immune checkpoint inhibitors (ICIs) have shown tremendous promise in many solid tumor malignancies. ICIs are monoclonal antibodies directed at immune checkpoint proteins, $\mathrm{T}$ cell surface signaling receptors, which play an important physiological role in dampening immune responses and preventing autoimmunity. ${ }^{3}$ Classically recognized immune checkpoints include programmed-death receptor 1 (PD-1) and cytotoxic T lymphocyte-associated protein 4 (CTLA-4).

PD-1 acts as a regulatory checkpoint during the effector stage of the immune response. ${ }^{4}$ On binding of its ligand, PD-L1, signaling pathways within the effector $\mathrm{T}$ cell result in reduced proliferation, decreased cytokine production, and diminished cytolytic function (Figure 1). ${ }^{4}$ Consequently, effector $\mathrm{T}$ cell function is significantly reduced. Tumors are able to take advantage of the PD-1:PD-L1 axis by up-regulating PD-L1 on their surface. ${ }^{5}$ When tumor-infiltrating lymphocytes interact with the tumor, they are effectively "turned off," allowing the tumor to evade the immune system. ${ }^{5}$ Alternatively, CTLA-4 effects its regulatory mechanism during $\mathrm{T}$ cell activation. ${ }^{4}$ CTLA-4 is expressed on the surface of naïve T cells and competes with CD28 to bind B7. ${ }^{6}$ By blocking the second signal in $\mathrm{T}$ cell activation, a state of anergy results in which the $\mathrm{T}$ cell cannot enter the effector phase (Figure 2). ${ }^{6}$ Furthermore, CTLA-4 is expressed on the surface of regulatory $\mathrm{T}$ cells $\left(\mathrm{T}_{\text {reg }}\right)$, allowing $\mathrm{T}_{\text {reg }}$ to bind and down-regulate B7 on antigen-presenting cells. ${ }^{7}$

Characterization of CTLA-4 and PD-1, led largely by James P. Allison and Tasuku Honjo, became the foundation for their role as therapeutic targets. By blocking these inhibitory checkpoints with monoclonal antibodies, the antitumor immune response is not dampened, and the effector phase is prolonged. ${ }^{7}$ To date, the US Food and Drug Administration (FDA) has approved at least 4 PD-1 inhibitors for use in 9 malignancies, including NSCLC. Of note, the 2018 Nobel Prize in Physiology or Medicine was awarded to Allison and Honjo for their work in discovering the "inhibition of negative regulation" as a cancer therapy.

\section{LANDSCAPE OF CHECKPOINT BLOCKADE IN NSCLC \\ Overview of Clinical Trials}

Clinical trials in advanced or metastatic NSCLC have focused primarily on the PD-1:PD-L1 axis, using anti-PD-1 (eg, nivolumab, pembrolizumab) and anti-PD-L1 (eg, atezolizumab, durvalumab) agents. Early trials compared PD-1 inhibitors to docetaxel as second-line therapy. Checkmate-017 and -057 demonstrated improved overall survival and response rates in both squamous and nonsquamous NSCLC with nivolumab, regardless of PD-L1 expression. In addition, Keynote-010 showed improved survival with 2 different doses of pembrolizumab compared with docetaxel, with efficacy correlated with surface PD-L1 expression. ${ }^{10}$

The efficacy of PD-1 inhibitors as second-line therapy in advanced NSCLC prompted trials to determine their potential as first-line agents. Keynote-024 examined pembrolizumab versus standard platinum-based chemotherapy in patients with untreated NSCLC with surface PD-L1 positivity $>50 \%$. The data showed not only improved median progression-free survival (10.3 months vs 6 months), but also a significantly higher response rate and duration of response than seen with platinum-based chemotherapy. ${ }^{11} \mathrm{~A}$ later trial, Keynote-042, demonstrated the efficacy of pembrolizumab as a first-line agent in patients with PD-L1 positivity $>1 \% .{ }^{12}$ Importantly, this trial and the previously mentioned trials have demonstrated that ICIs have a safety profile comparable to or better than that of traditional chemotherapy. ${ }^{10-12}$

Additional trials, notably Keynote-189, Keynote-407, and IMpower 150, have shown efficacy in combining ICIs (pembrolizumab or atezolizumab plus bevacizumab) with chemotherapy, regardless of the patient's tumor surface PD-L1 expression. ${ }^{13-15}$ Furthermore, the PACIFIC trial established a role for durvalumab as consolidation therapy for patients with stage III unresectable NSCLC who do not progress after concurrent chemoradiation. ${ }^{16}$

Combination immunotherapy has been explored as well. Checkmate-227 compared the combination of nivolumab and ipilimumab with standard chemotherapy as first-line therapy in patients with recurrent or metastatic NSCLC. The data showed superior progression-free survival with combination nivolumab and ipilimumab therapy ( $43 \%$ vs $13 \%$ at 1 year) in patients with a high tumor mutational burden, regardless of PD-L1 expression. ${ }^{17}$ Importantly, this study reinforced tumor mutational burden as a potential biomarker for the response to checkpoint inhibition; however, further work is necessary to evaluate this relationship and optimize combination immunotherapies.

\section{Current Use of ICIs in NSCLC}

The success of the aforementioned trials has shifted the management of late-stage NSCLC to prominently feature ICIs in the treatment paradigm. ${ }^{18}$ At present, the FDA has approved 4 ICIs for various indications in advanced or metastatic NSCLC (Table 1). Nivolumab was the first agent approved for second-line therapy in 2015, followed by pembrolizumab. The FDA has since expanded the indication for pembrolizumab by approving its use as a first-line agent in patients with advanced or metastatic NSCLC and PD-L1 


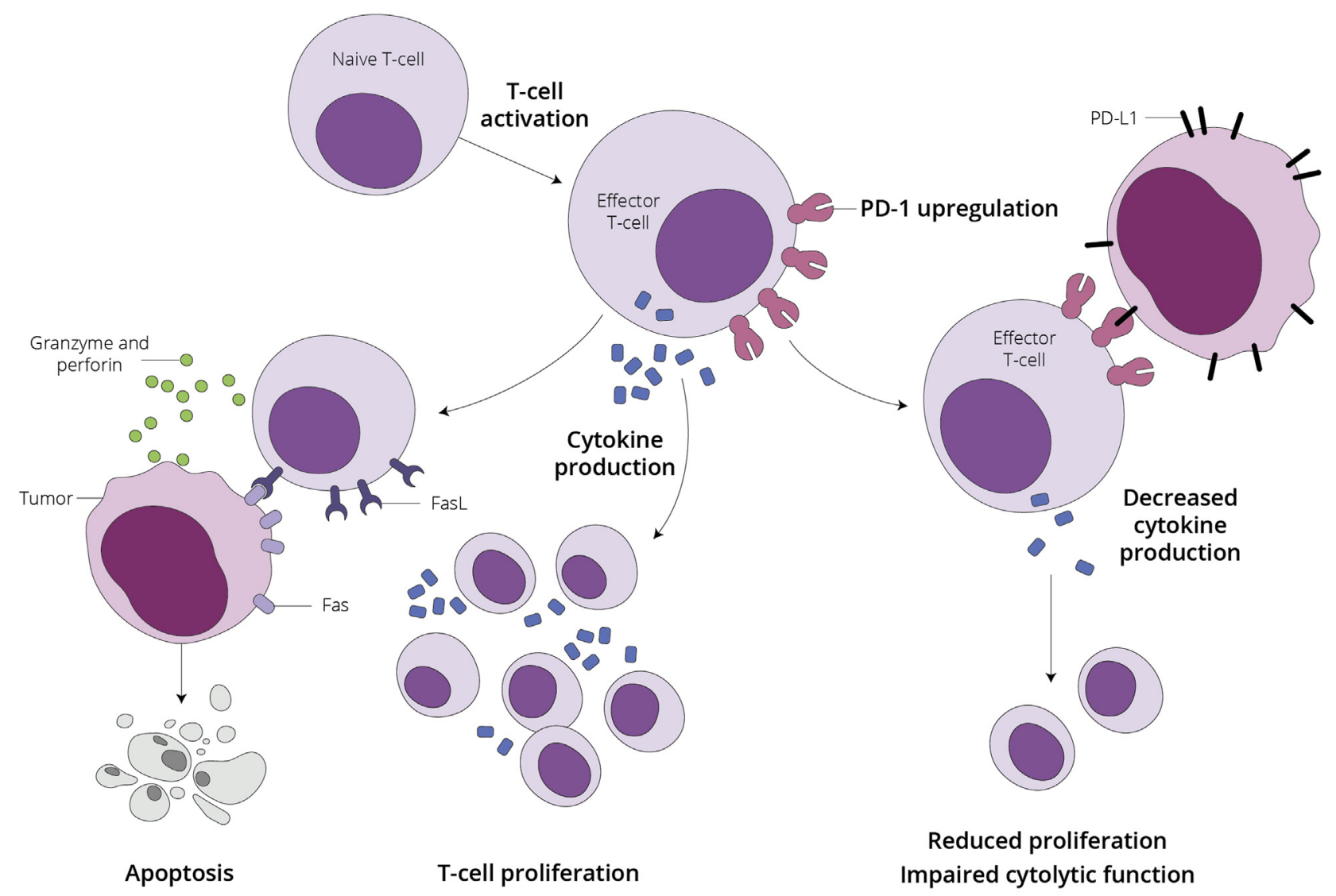

(c) Duke University 2018

FIGURE 1. The role of the PD-1:PD-L1 axis in regulating immune responses $P D-L 1$, Programmed-death receptor 1 ligand.

positivity $(>1 \%)$. In addition, the FDA has approved durvalumab for consolidation therapy and other combination ICIchemotherapy regimens as first-line therapy.

Today, numerous regimens are available to treat advanced NSCLC. Molecular characteristics such as PD-L1 expression, tumor mutation burden, and $A L K$ or $E G F R$ genomic aberrations are used to guide optimal therapy. ${ }^{18}$ Contraindications for treatment with ICI include autoimmune disease and current use of immunosuppressive agents. ${ }^{18}$ ICIs have lower response rates in patients with $A L K$ or $E G F R$ mutations, and thus these agents are relegated to the second-line setting in this population. Immune-related toxicities, including pneumonitis, thyroiditis, hypophysitis, and others, can occur with ICI therapy, although effective toxicity treatment algorithms have been developed. Our understanding continues to evolve and to inform questions for future studies and expanding indications.

\section{NEOADJUVANT CHECKPOINT BLOCKADE FOR \\ NSCLC}

Motivations

Surgery is the mainstay of curative treatment for early-stage NSCLC (stage I-IIIA); however, many patients will experience postsurgical recurrence. ${ }^{19}$ Receipt of chemotherapy during the perioperative period prolongs survival, but the impact is limited. ${ }^{19}$ Better adjuncts are needed for early-stage NSCLC. Neoadjuvant PD-1 blockade potentially could produce a benefit, given that patients with early-stage disease have better baseline immune status and less tumor heterogeneity than patients with advanced or metastatic disease. ${ }^{20}$ In addition, with the primary tumor in place as an antigen source, a more robust immune response with expansion of $\mathrm{T}$ cell clones that can surveil for recurrence and systemic micrometastasis may be possible. ${ }^{20}$ Furthermore, the neoadjuvant treatment paradigm allows for analysis of the resected tumor to discover and better understand factors associated with immune sensitivity and resistance.

Some of these hypotheses have been examined in the preclinical setting. In models of spontaneously metastatic breast cancer, Liu and colleagues $^{21}$ demonstrated prolonged survival in mice receiving neoadjuvant ICI compared with those receiving adjuvant ICI following primary tumor resection. This survival benefit was $\mathrm{CD} 8^{+}$ $\mathrm{T}$ cell-dependent, and levels of tumor-specific $\mathrm{CD} 8^{+} \mathrm{T}$ cells in peripheral blood and lymphoid organs correlated 

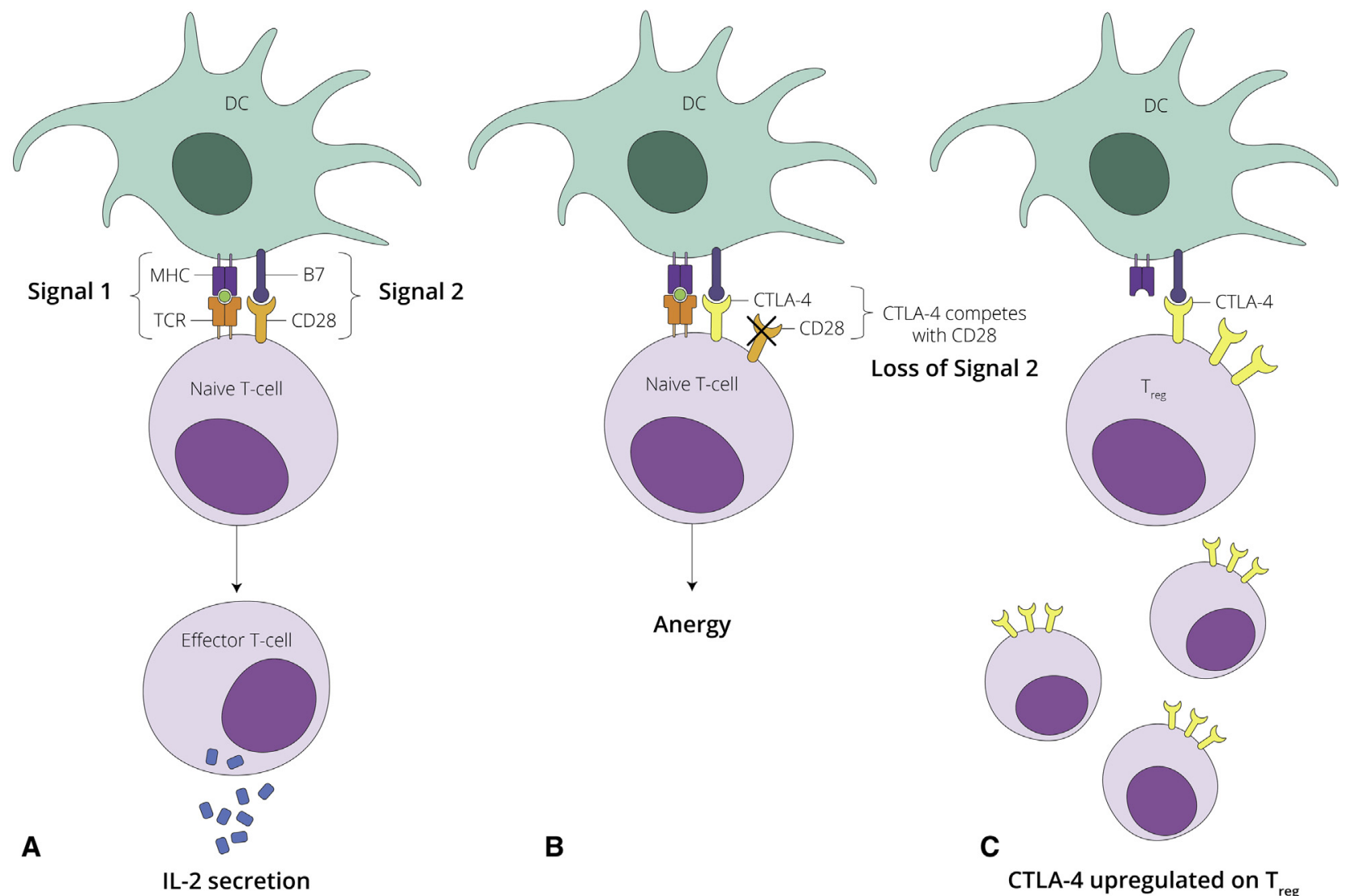

IL-2 secretion

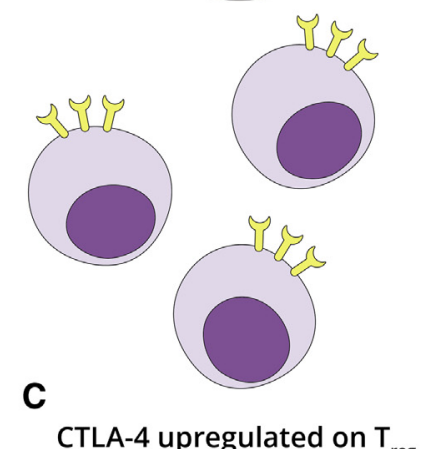

Duke University 2018

FIGURE 2. CTLA-4 as an immune checkpoint. A, T cell activation requires 2 signals: T cell receptor (TCR) and major histocompatibility complex (MHC) interaction and CD28-B7 binding. B, CTLA-4 on naive T cells competes with CD28 to bind B7 and prevent the second, costimulatory signal in T cell activation. C, CTLA-4 is expressed on regulatory Tregs to further suppress effector T cells. CTLA-4, Cytotoxic T lymphocyte-associated protein 4. (Illustrated by Megan Llewellyn, MSMI; copyright (C Duke University, with permission under a CC-BY 4.0 license.)

with survival. ${ }^{21}$ This finding has been translated clinically. Early reports from the ongoing Keynote-173 trial demonstrated the feasibility of neoadjuvant pembrolizumab plus chemotherapy in triple-negative breast cancer, with promising pathological response rates and tolerable adverse events. $^{22}$ Similarly, preliminary data from the phase 2 I-SPY2 trial supports a role for neoadjuvant ICI therapy, reporting improved pathological response rates compared with controls for both $\mathrm{HR}^{+} / \mathrm{HER}^{-}$and triple-negative breast cancers. ${ }^{23}$

Similar results have been observed in early-phase trials in melanoma. OpACIN, a phase $1 \mathrm{~b}$ trial, randomized patients with high-risk stage III melanoma to neoadjuvant or adjuvant ipilimumab plus nivolumab. ICI delivery in these settings was feasible, with all patients undergoing surgery; however, the rate of adverse events was high, and only 2 patients completed the regimen. ${ }^{24}$ Interestingly, the RECIST-defined responses underestimated the pathological response. ${ }^{24}$ Taken together, the results of these preclinical studies and early trials provide a further rationale for pursuing neoadjuvant ICI therapy for NSCLC.

\section{Potential Surgical Implications}

Immunotherapy is gaining exponential traction in clinical practice. The expansion of ICI use to the neoadjuvant setting has a solid scientific foundation; however, the feasibility of using these agents in surgical patients is unclear. Several concerns should be considered when designing trials and interpreting the results, including the optimal interval between drug delivery and surgery. Drug toxicities may alter the surgical timeline, and delays may occur. One such toxicity, pneumonitis, is of particular concern for thoracic surgeons because it may compromise pulmonary function, and how surgery and anesthesia impact this autoimmune side effect is unclear. ${ }^{25}$ Furthermore, many toxicities associated with ICIs necessitate treatment with systemic corticosteroids, which may impact healing in the postoperative period. However, it should be noted that many immune-related adverse events arise at 
TABLE 1. Food and Drug Administration-approved checkpoint inhibitors for NSCLC

\begin{tabular}{|c|c|c|c|c|c|}
\hline $\begin{array}{l}\text { Checkpoint } \\
\text { inhibitor }\end{array}$ & Trade name & Target & $\begin{array}{c}\text { FDA } \\
\text { approval }\end{array}$ & Indications & Trials \\
\hline Nivolumab & $\begin{array}{l}\text { Opdivo } \\
\text { (BMS) }\end{array}$ & PD-1 & 2015 & $\begin{array}{l}\text { Metastatic NSCLC with progression on platinum-doublet } \\
\text { chemotherapy }\end{array}$ & $\begin{array}{l}\text { Checkmate } 017 \\
\text { Checkmate } 057\end{array}$ \\
\hline Pembrolizumab & $\begin{array}{l}\text { Keytruda } \\
\text { (Merck) }\end{array}$ & PD-1 & 2015,2016 & $\begin{array}{l}\text { First-line therapy in advanced (unresectable stage III) or } \\
\text { metastatic NSCLC if PD-L } 1>1 \% \text { and no EGFR/ALK } \\
\text { aberrations; first-line combination therapy for both } \\
\text { advanced nonsquamous and squamous pathology }\end{array}$ & $\begin{array}{l}\text { Keynote } 010 \\
\text { Keynote } 024 \\
\text { Keynote } 042 \\
\text { Keynote } 189 \\
\text { Keynote } 407\end{array}$ \\
\hline Durvalumab & $\begin{array}{l}\text { Imfinzi } \\
\quad \text { (AstraZeneca) }\end{array}$ & PD-L1 & 2018 & $\begin{array}{l}\text { Consolidation therapy for unresectable stage III NSCLC in } \\
\text { patients with no progression on } 2 \text { or more cycles of } \\
\text { definitive concurrent chemoradiation }\end{array}$ & PACIFIC \\
\hline Atezolizumab & $\begin{array}{l}\text { Tecentriq } \\
\quad \text { (Genentech) }\end{array}$ & PD-L1 & 2018 & $\begin{array}{l}\text { Combination atezolizumab-bevacizumab-paclitaxel/ } \\
\text { carboplatin as first-line therapy in metastatic } \\
\text { nonsquamous NSCLC, with no EGFR or } A L K \text { aberrations; } \\
\text { single-agent atezolizumab in metastatic NSCLC with } \\
\text { disease progression on platinum chemotherapy }\end{array}$ & $\begin{array}{l}\text { IMpower150 } \\
\text { Pivotal OAK } \\
\text { POPLAR }\end{array}$ \\
\hline
\end{tabular}

$\overline{F D A}$, Food and Drug Administration; BMS, Bristol Meyer Squibb; $N S C L C$, non-small cell lung cancer; $P D$-1, programmed-death receptor 1; $P D-L 1$, programmed-death receptor 1 ligand.

$>6$ weeks into treatment and thus are less likely to occur in the neoadjuvant time frame.

Traditionally, patients receiving neoadjuvant therapy undergo repeat imaging before surgery, which can demonstrate disease response, stability, or progression. "Pseudoprogression" has been described in patients who receive immunotherapy. ${ }^{26}$ This radiographic phenomenon, which appears as disease progression of the primary tumor or lymph nodes, is actually an inflammatory response; however, it is very difficult to distinguish. ${ }^{26}$ Pseudoprogression is less common in NSCLC than in melanoma but has been reported. The evaluation and management of patients who demonstrate pseudoprogression need to be addressed-in particular, how pseudoprogression may impact surgical planning or the decision to proceed with resection.

In addition, the impact of ICI therapy on the technical aspects of surgery and its oncologic efficacy remain unclear. The inflammatory response following receipt of ICIs may result in inflammation or hypervascularity, which increases the operative difficulty and duration of the procedure. At institutions where the majority of thoracic surgery is minimally invasive, neoadjuvant immunotherapy may affect the surgeon's approach and conversion rate. Furthermore, oncologic outcomes to consider include lymph node retrieval, margins, and pathological staging.

\section{Current Literature and Ongoing Trials}

At this time, there are few published studies examining ICI as neoadjuvant therapy for early-stage NSCLC. In a small case series, Chaft and colleagues ${ }^{25}$ reported their experience operating on patients with late-stage NSCLC, who demonstrated remarkable disease responses to ICI therapy. One patient developed pneumonitis necessitating corticosteroid treatment, which delayed the surgery. This patient's surgery was technically challenging, requiring conversion from robot-assisted to open thoracotomy; however, other patients did not require conversion, and all underwent R0 resection. ${ }^{25}$ The sole postoperative complication was a prolonged air leak. ${ }^{25}$ Although not true neoadjuvant therapy, these cases demonstrate that operating after receipt of ICIs is feasible and highlight some of the technical considerations that must be examined in trials.

In a subsequent study of ICI as induction therapy, Yang and colleagues ${ }^{27}$ reported the surgical outcomes of the TOP1201 trial, a phase 2 trial comparing induction chemotherapy in combination with ipilimumab in patients with stage IB-IIIA NSCLC and historical controls. The results showed comparable postoperative complication rates, and the authors concluded that ipilimumab is safe and feasible as induction therapy. ${ }^{27}$ More recently, Forde and colleagues ${ }^{20}$ reported the findings of a phase 1 trial examining neoadjuvant nivolumab in untreated, resectable NSCLC. They found "acceptable safety" with no delays in surgery for the 21 patients undergoing resection. Forty-five percent of the patients had a major pathological response irrespective of PD-L1 expression; however, response was correlated with tumor mutational burden.

Preliminary results from ongoing trials have been presented in recent years. The NADIM study, a phase 2 trial examining neoadjuvant chemotherapy plus nivolumab followed by adjuvant nivolumab for 1 year in stage IIIA NSCLC, demonstrated unusually high objective response rates $\left(69.2 \%\right.$ complete pathological response). ${ }^{28}$ At this interim analysis, there were no delays in surgery, and all tumors were deemed resectable $(n=13) .{ }^{28}$ Similarly, interim analysis of the LCMC3 study examining 
TABLE 2. Ongoing clinical trials examining neoadjuvant checkpoint blockade in NSCLC

\begin{tabular}{|c|c|c|c|c|}
\hline Trial identifier & Trial name & Phase & Patient population & Intervention \\
\hline NCT03197467 & $\begin{array}{l}\text { Neoadjuvant Anti-PD-1 Immunotherapy } \\
\text { in Resectable NSCLC (NEOMUN) }\end{array}$ & Phase 2 & NSCLC stage II/IIIA & Pembrolizumab \\
\hline NCT02938624 & $\begin{array}{l}\text { Anti-PD-1 Neo-Adjuvant Treatment for } \\
\text { NSCLC }\end{array}$ & Phase 1 & NSCLC stage I/II & $\begin{array}{l}\text { Pembrolizumab (different doses and } \\
\text { intervals) }\end{array}$ \\
\hline NCT02818920 & Neoadjuvant Pembrolizumab & Phase 2 & NSCLC stage IB-IIIA & $\begin{array}{l}\text { Pembrolizumab ( } 2 \text { cycles before surgery, } \\
4 \text { cycles after surgery and standard } \\
\text { adjuvant therapy) }\end{array}$ \\
\hline NCT02158129 & $\begin{array}{l}\text { Nivolumab with or without Ipilimumab } \\
\text { or Chemotherapy in Treating Patients } \\
\text { with Previously Untreated Stage I-IIIA } \\
\text { NSCLC (NEOSTAR) }\end{array}$ & Phase 2 & NSCLC stage I-IIIA & $\begin{array}{l}\text { Nivolumab ( } 3 \text { doses) with or without } \\
\text { ipilimumab ( } 1 \text { dose) with or without } \\
\text { cisplatin/ docetaxel/pemetrexed }\end{array}$ \\
\hline NCT02259621 & $\begin{array}{l}\text { Neoadjuvant Nivolumab, or Nivolumab } \\
\text { in combination with Ipilimumab, in } \\
\text { resectable NSCLC }\end{array}$ & Phase 2 & NSCLC & $\begin{array}{l}\text { Nivolumab ( } 3 \text { doses), nivolumab plus } \\
\text { ipilimumab }\end{array}$ \\
\hline NCT03732664 & $\begin{array}{l}\text { Neoadjuvant Nivolumab in Resectable } \\
\text { NSCLC }\end{array}$ & Phase 1 & $\begin{array}{l}\text { High-risk resectable } \\
\text { NSCLC }\end{array}$ & Nivolumab (3 doses) \\
\hline NCT03808480 & $\begin{array}{l}\text { Nivolumab after Cyclophosphamide and } \\
\text { Doxorubicin Induction therapy in } \\
\text { NSCLC with PD-L1 }<10 \%\end{array}$ & Phase 2 & Nonsquamous NSCLC & $\begin{array}{l}\text { Cyclophosphamide, doxorubicin, and } \\
\text { nivolumab }\end{array}$ \\
\hline NCT03623776 & $\begin{array}{l}\text { Neoadjuvant JS001, or JS001 in } \\
\text { Combination with Pemetrexed and } \\
\text { Carboplatin in Resectable NSCLC }\end{array}$ & Phase 2 & NSCLC & $\begin{array}{l}\text { JS001 (toripalimab) alone, } 3 \text { cycles; } \\
\text { JS001 plus chemotherapy, } 3 \text { cycles }\end{array}$ \\
\hline NCT03030131 & $\begin{array}{c}\text { Immune Neoadjuvant Therapy Study of } \\
\text { Durvalumab in Early Stage NSCLC }\end{array}$ & Phase 2 & NSCLC stage IB-II & Durvalumab (3 doses) \\
\hline NCT03694236 & $\begin{array}{l}\text { Concurrent Neoadjuvant } \\
\text { Chemoradiotherapy Plus Durvalumab } \\
\text { (MEDI4736) in Resectable Stage II/ } \\
\text { IIIA NSCLC }\end{array}$ & Phase $1 / 2$ & $\begin{array}{l}\text { NSCLC, potentially } \\
\text { resectable stage II/IIIA }\end{array}$ & $\begin{array}{l}\text { Durvalumab, paclitaxel/ carboplatin, } \\
\text { radiation (45 Gy) }\end{array}$ \\
\hline NCT02572843 & Anti-PD-L1 in Stage IIIA (N2) NSCLC & Phase 2 & $\begin{array}{l}\text { NSCLC stage IIIA (N2), } \\
\text { resectable }\end{array}$ & $\begin{array}{l}\text { Neoadjuvant: chemotherapy ( } 3 \text { cycles } \\
\text { cisplatin/docetaxel), followed by } \\
\text { durvalumab ( } 2 \text { cycles) } \\
\text { Adjuvant: } \\
\text { - R0 resection: durvalumab } \\
\text { - R1/R2 resection: radiation plus } \\
\text { durvalumab }\end{array}$ \\
\hline NCT02927301 & $\begin{array}{l}\text { A Study of Atezolizumab as Neoadjuvant } \\
\text { and Adjuvant Therapy in Resectable } \\
\text { NSCLC (LCMC3) }\end{array}$ & Phase 2 & $\begin{array}{l}\text { NSCLC stage IB-IIIB, } \\
\text { resectable }\end{array}$ & $\begin{array}{l}\text { Neoadjuvant atezolizumab ( } 2 \text { cycles); } \\
\text { adjuvant atezolizumab in responders } \\
\text { (up to } 1 \text { year) }\end{array}$ \\
\hline NCT02716038 & $\begin{array}{l}\text { Neoadjuvant MPDL3280A, Nab- } \\
\text { paclitaxel and Carboplatin (MAC) in } \\
\text { NSCLC }\end{array}$ & Phase 2 & NSCLC & $\begin{array}{l}\text { MPDL3280A (atezolizumab up to } 4 \\
\text { cycles) }\end{array}$ \\
\hline NCT02994576 & $\begin{array}{l}\text { Atezolizumab as Induction Therapy in } \\
\text { NSCLC }\end{array}$ & Phase 2 & $\begin{array}{l}\text { NSCLC, stage IB-IIIA, } \\
\text { non-N2 }\end{array}$ & Atezolizumab (single dose) \\
\hline
\end{tabular}

NSCLC, Non-small cell lung cancer.

neoadjuvant atezolizumab monotherapy for stage IB-IIIB resectable NSCLC reported a $21 \%$ rate of major pathological response and no major delays in surgery. ${ }^{29}$ In a recent presentation, the NEOSTAR phase 2 trial demonstrated higher rates of major pathological response in patients receiving combination nivolumab plus ipilimumab compared with those receiving nivolumab monotherapy before surgery. ${ }^{30}$ Overall, both therapeutic regimens were well tolerated; however, surgical complications included 2 bronchopleural fistulas and 8 air leaks. ${ }^{30}$

These early results are promising from a feasibility and safety standpoint. They suggest limited surgical delays and adequate resection; however, the technical considerations in using these therapies preoperatively has generated little discussion to date. Additional phase 1 and 2 clinical trials are recruiting in the United States and 
abroad (Table 2). The conclusion of these studies and full publication of their results is eagerly awaited.

\section{FUTURE DIRECTIONS AND DILEMMAS}

The prospect of using ICIs in the neoadjuvant setting is an exciting addition to the treatment of early-stage NSCLC. Future studies will undoubtedly include phase 3 trials to compare the efficacy of this approach with that of standard practices. Although primary outcomes will focus on survival and pathological response, secondary outcomes should include surgical considerations (eg, delays, operative length, changes in approach, postoperative complications, hospital length of stay) and immediate oncologic findings (eg, lymph node retrieval, margin status). These variables will be important to thoracic surgeons and medical oncologists in establishing guidelines if ICIs are determined to be efficacious in this setting. Fine-tuning the integration of ICI therapy with surgery will likely be an extensive process, requiring continual study and quality improvement.

It should be noted that the response rates to ICIs are not universal. Predicting which patients will respond remains an important goal. Currently, PD-L1 expression and tumor mutation burden are recognized as predictors of response; however, they are not always reliable correlates. Further inquiry is needed to better identify "responders." The use of neoadjuvant ICI therapy has the potential advantage of using pathological response as a way to identify patients who will benefit from prolonged and expensive adjuvant therapy. Identifying additional biomarkers will increase the ability to tailor oncologic care to individual patients. Furthermore, they may expand our understanding of response and perhaps unlock mechanisms to enhance or broaden this efficacy to others.

An additional challenge for the future of ICIs is staving off drug resistance. At present, long-term survival data are limited in NSCLC. Response durability and the development of resistance remain to be determined. Combination therapy is a potential strategy for expanding response rates and avoiding resistance. Creative combinations abound and may include combining ICIs, targeting immunostimulatory pathways, and other modes of immunotherapy.

\section{CONCLUSION}

Increasing understanding of the immune system's role in regulating and suppressing cancer continues to fuel the study of ICIs. There is great momentum in determining their utility in resectable NSCLC. As the literature expands, we anticipate a more thorough understanding of the impact of ICIs on oncologic resection. Further characterization of this relationship is vital to the effective integration of checkpoint inhibition with surgical management for early-stage NSCLC.

\section{Conflict of Interest Statement}

Authors have nothing to disclose with regard to commercial support.

\section{References}

1. Doll R, Kinlen L. Immunosurveillance and cancer: epidemiological evidence. Br Med J. 1970;4:420-2

2. Fouad YA, Aanei C. Revisiting the hallmarks of cancer. Am J Cancer Res. 2017; 7:1016-36.

3. Mellman I, Coukos G, Dranoff G. Cancer immunotherapy comes of age. Nature. 2011;480:480-9.

4. Parry RV, Chemnitz JM, Frauwirth KA, Lanfranco AR, Braunstein I, Kobayashi SV, et al. CTLA-4 and PD-1 receptors inhibit T-cell activation by distinct mechanisms. Mol Cell Biol. 2005;25:9543-53.

5. Iwai Y, Ishida M, Tanaka Y, Okazaki T, Honjo T, Minato N. Involvement of PD-L1 on tumor cells in the escape from host immune system and tumor immunotherapy by PD-L1 blockade. Proc Natl Acad Sci U S A. 2002;99:12293-7.

6. Engelhardt JJ, Sullivan TJ, Allison JP. CTLA-4 overexpression inhibits T cell responses through a CD28-B7-dependent mechanism. J Immunol. 2006;177: 1052-61.

7. Peggs KS, Quezada SA, Chambers CA, Korman AJ, Allison JP. Blockade of CTLA-4 on both effector and regulatory $\mathrm{T}$ cell compartments contributes to the antitumor activity of anti-CTLA-4 antibodies. J Exp Med. 2009;206: 1717-25.

8. Borghaei H, Paz-Ares L, Horn L, Spigel DR, Steins M, Ready NE, et al. Nivolumab versus docetaxel in advanced nonsquamous non-small-cell lung cancer. N Engl J Med. 2015;373:1627-39.

9. Brahmer J, Reckamp KL, Baas P, Crinò L, Eberhardt WE, Poddubskaya E, et al. Nivolumab versus docetaxel in advanced squamous-cell non-small-cell lung cancer. N Engl J Med. 2015;373:123-35.

10. Herbst RS, Baas P, Kim DW, Felip E, Pérez-Garcia JL, Han JY, et al. Pembrolizumab versus docetaxel for previously treated, PD-L1-positive, advanced non-small-cell lung cancer (KEYNOTE-010): a randomised controlled trial. Lancet. 2016;387:1540-50.

11. Reck M, Rodríguez-Abreu D, Robinson AG, Hui R, Csőszi T, Fülöp A, et al. Pembrolizumab versus chemotherapy for PD-L1-positive non-small-cell lung cancer. N Engl J Med. 2016;375:1823-33.

12. Mok TSK, Wu YL, Kudaba I, Kowalski DM, Cho BC, Turna HZ, et al. Pembrolizumab versus chemotherapy for previously untreated, PD-L1expressing, locally advanced or metastatic non-small-cell lung cancer (KEYNOTE-042): a randomised, open-label, controlled, phase 3 trial. Lancet. 2019;393:1819-30.

13. Socinski MA, Jotte RM, Cappuzzo F, Orlandi F, Stroyakovskiy D, Nogami N, et al. Atezolizumab for first-line treatment of metastatic nonsquamous NSCLC. N Engl J Med. 2018;378:2288-301.

14. Gandhi L, Rodríguez-Abreu D, Gadgeel S, Esteban E, Felip E, De Angelis F, et al. Pembrolizumab plus chemotherapy in metastatic non-small-cell lung cancer. N Engl J Med. 2018;378:2078-92.

15. Paz-Ares L, Luft A, Vicente D, Tafreshi A, Gümüș M, Mazières J, et al. Pembrolizumab plus chemotherapy for squamous non-small-cell lung cancer. N Engl J Med. 2018;379:2040-51.

16. Antonia SJ, Villegas A, Daniel D, Vicente D, Murakami S, Hui R, et al. Overall survival with durvalumab after chemoradiotherapy in stage III NSCLC. $N$ Engl J Med. 2018;379:2342-50.

17. Hellmann MD, Ciuleanu TE, Pluzanski A, Lee JS, Otterson GA, AudigierValette C, et al. Nivolumab plus ipilimumab in lung cancer with a high tumor mutational burden. N Engl J Med. 2018;378:2093-104.

18. National Comprehensive Cancer Network. NCCN clinical practice guidelines in oncology: non-small cell lung cancer. 2019. Available at: https://www.nccn.org/ professionals/physician_gls/default.aspx\#site. Accessed June 18, 2019.

19. Hirsch FR, Scagliotti GV, Mulshine JL, Kwon R, Curran WJ Jr, Wu YL, et al. Lung cancer: current therapies and new targeted treatments. Lancet. 2017;389: 299-311. 
20. Forde PM, Chaft JE, Smith KN, Anagnostou V, Cottrell TR, Hellmann MD, et al. Neoadjuvant PD-1 blockade in resectable lung cancer. N Engl J Med. 2018;378:1976-86.

21. Liu J, Blake SJ, Yong MC, Harjunpää H, Ngiow SF, Takeda K, et al. Improved efficacy of neoadjuvant compared to adjuvant immunotherapy to eradicate metastatic disease. Cancer Discov. 2016;6:1382-99.

22. Schmid P, Park YH, Muñoz-Couselo E, Kim SB, Sohn J, Im SA, et al Pembrolizumab (pembro) + chemotherapy (chemo) as neoadjuvant treatment for triple- negative breast cancer (TNBC): preliminary results from KEYNOTE-173. J Clin Oncol. 2017;35(Suppl):abstr 556.

23. Nanda R, Liu MC, Yau C, Asare S, Hylton N, Veer LV, et al. Pembrolizumab plus standard neoadjuvant therapy for high-risk breast cancer (BC): results from I-SPY 2. J Clin Oncol. 2017;35(Suppl):abstr 506.

24. Blank CU, Rozeman EA, Fanchi LF, Sikorska K, van de Wiel B, Kvistborg P, et al. Neoadjuvant versus adjuvant ipilimumab plus nivolumab in macroscopic stage III melanoma. Nat Med. 2018;24:1655-61.

25. Chaft JE, Hellmann MD, Velez MJ, Travis WD, Rusch VW. Initial experience with lung cancer resection after treatment with T-cell checkpoint inhibitors. Ann Thorac Surg. 2017;104:e217-8.
26. Chiou VL, Burotto M. Pseudoprogression and immune-related response in solic tumors. J Clin Oncol. 2015;33:3541-3.

27. Yang CJ, McSherry F, Mayne NR, Wang X, Berry MF, Tong B, et al. Surgical outcomes after neoadjuvant chemotherapy and ipilimumab for non-small cell lung cancer. Ann Thorac Surg. 2018;105:924-9.

28. Provencio-Pulla M, Nadal-Alforja E, Cobo M, Insa A, Costa Rivas M, Majem M, et al. Neoadjuvant chemo/immunotherapy for the treatment of stage IIIA resectable non-small cell lung cancer (NSCLC): a phase II multicenter exploratory study-NADIM study-SLCG. J Clin Oncol. 2018 36(Suppl):8521.

29. Rusch VW, Chaft JE, Johnson B, Wistuba II, Kris MG, Lee JM, et al. Neoadjuvant atezolizumab in resectable non-small cell lung cancer (NSCLC) initial results from a multicenter study (LCMC3). J Clin Oncol. 2018; 36(Suppl):8541.

30. Cascone T, William WN, Weissferdt A, Lin HY, Leung CH, Carter BW, et al. Neoadjuvant nivolumab $(\mathrm{N})$ or nivolumab plus ipilimumab (NI) for resectable non-small cell lung cancer (NSCLC): clinical and correlative results from the NEOSTAR study. J Clin Oncol. 2019;37(Suppl):8504. 